\title{
Nicotinate-Nucleotide Pyrophosphorylase [Carboxylating]
}

National Cancer Institute

\section{Source}

National Cancer Institute. Nicotinate-Nucleotide Pyrophosphorylase [Carboxylating]. NCI Thesaurus. Code C112839.

Nicotinate-nucleotide pyrophosphorylase [carboxylating] (297 aa, $\sim 31 \mathrm{kDa}$ ) is encoded by the human QPRT gene. This protein is involved in the synthesis of nicotinamide adenine dinucleotide. 